\title{
On the Foundation for Roles in RM-ODP: Contributions from Conceptual Modelling
}

\author{
João Paulo A. Almeida ${ }^{1,2}$ and Giancarlo Guizzardi ${ }^{1,3}$ \\ ${ }^{1}$ Federal University of Espirito Santo, Brazil \\ ${ }^{2}$ Centre for Telematics and Information Technology, University of Twente, The Netherlands \\ ${ }^{3}$ Laboratory for Applied Ontology (LOA), ISTC-CNR, Trento, Italy \\ jpalmeida@ieee.org,guizzardi@loa-cnr.it
}

\begin{abstract}
In this paper, we attempt to provide a semantic foundation for the role-related concepts in the RM-ODP. We believe that some theories of conceptual modelling may help us to provide a well-founded underpinning for these concepts, and to harmonize competing proposals for them. As a starting point of our effort, we study the definitions of Genilloud and Wegmann, and the proposed definition in the Working Document for the amendment of the standard as contributed by Linington.
\end{abstract}

Keywords: roles, RM-ODP, conceptual modelling, conceptual foundations, systems specification

\section{Introduction}

The Reference Model for Open Distributed Processing (RM-ODP) includes in its Part 2 [12] a foundational conceptual framework upon which the whole standard is based (the "Foundations"). This conceptual framework is meant to clarify key assumptions about how systems can be structured and specified [13] and defines important terms and concepts to refer to ODP systems.

Among these are the concepts of "object", "interface", "roles" and "bindings". These concepts are used to talk about the organization and behaviour of a system in terms of abstract entities (objects) which interact by performing shared behaviour. In a nutshell, the conceptualization defined in the Foundations determines that objects interact by performing interactions, which occur at the bindings between interfaces of interacting objects, some of which may fulfil particular (object) roles in shared behaviour.

While the concepts and definitions of the RM-ODP foundations have been very influential and are taken to be a reference for the modelling of open systems, some of these concepts or their definitions have been subject of criticism, debate and revision in the literature $[1,13,16]$. We believe this serves to strengthen the definitions and to further consolidate the RM-ODP conceptualization as a solid foundation which can serve as a basis for communication, consensus and standardization in the context of open systems.
In this paper, we attempt to provide a semantic foundation for the role-related concepts the RM-ODP foundations. We believe that some theories of conceptual modelling (as consolidated in [5]) may help us to provide a wellfounded underpinning for these concepts, and to harmonize competing proposals for them.

The concept of role has attracted considerable attention not only in the scope of the revision of the RM-ODP [1, 13], but also in the scope of the general literature in object-oriented modelling (e.g., $[19,18,21])$ and conceptual modelling (e.g., $[5,3,4,14,15,18,19])$. We believe that the concept of "role" as defined in RM-ODP can profit significantly from a revised definition, which should not only clarify it in the scope of the standard, but ensure alignment with the current understanding of the concept as applied in the modelling literature.

\section{Definitions of role in the scope of the RM-ODP}

\subsection{Definitions}

We start by examining the definition of role as provided in the standard and summarizing here the proposals and observations made in $[1,11,13]$ which seem to capture improved understanding of the concept in the RMODP expert community since the writing of the standard.

The current definition captured in RM-ODP Part 2 reads [12]:

"Role: Identifier for a behaviour, which may appear as a parameter in a template for a composite object, and which is associated with one of the component objects of the composite object.

Specification of a template as a composition of roles enables the instantiation process to be explained as the association of a specific component of the resultant composite object with each role. The association of a component object with a role may result from the actualization of a parameter."

Proposed definition 1 (quoted from [1]) reads:

"Role: An abstraction of the behaviour of an object that consists of a subset of the interactions of that object together with a set of constraints on when they may occur. A role always be- 
longs to a specific larger behaviour that involves other roles, called a collaborative behaviour."

"Role Template: The specification of the common features of a collection of roles in sufficient detail that a role can be instantiated using it....

Collaborative Behaviour Template: The specification of the common features of a collection of collaborative behaviours in sufficient detail that a collaborative behaviour can be instantiated using it...."

Proposed definition 2 (quoted from Working Draft of the "Amendment to ITU T X.901-3 | ISO/IEC 10746 Information Technology" [11], Section 1.1, Contributor UK):

"Role: A formal placeholder in the specification of a template for a composite object. It identifies the behaviour of some component object within the composite and links that behaviour to an actual object in an instantiation of the composite. In order to satisfy the specification, the actual object is required to exhibit the specified behaviour. It is then said to fulfil the role in the instantiation of the template."

"Thus, the template for a composite object is specified as a composition of roles, which parameterize that template. The instantiation process binds a specific component object of the resultant composite object to each role parameter.

Note - Any agreement governing shared behaviour of two or more objects implicitly defines a template for a composite object and the roles of those objects in that composite object. Thus, roles are defined by interactions (8.3), contracts (11.2.1), liaisons (13.2.4) and bindings (13.4.2)."

In these two proposed revisions of the definition, it is clear that roles are always used in the scope of a particular relationship between objects, in the context of which the objects exhibit particular (contingent) behaviours. This is confirmed by the usage of the concept of role in the conceptual modelling literature as discussed in $[5,19]$ and as quoted in [2]: "as suggested by the work of Sowa and Guarino, a role is meaningful only in the context of a relationship." This seems to have been the intention in the original definition of the standard as well, so we can conclude that no definition of role should deviate from this essential characteristic.

Examining the proposed definitions further, the following divergence can be observed: proposed definition 2 talks about a composite object and the participation of components in this composite object, while proposed definition 1 talks about participation in a collaborative behaviour. We observe that, despite the apparent divergence, the definitions seem to emphasize dual aspects of the same phenomenon. The justification is as follows: given the collaborative behaviour referred to in proposed definition 1, take the objects that participate in this collaborative behaviour and compose them. The obtained composite object is the one referred to in proposed definition 2. The suggested note for the proposed definition 2 in [11] clarifies further this dual relation (now from the perspective of definition 2) when it states that "Any agree- ment governing shared behaviour of two or more objects implicitly defines a template for a composite object and the roles of those objects in that composite object".

Definition 1 makes it clear that roles have the same standing as the concepts of objects, interfaces and actions with respect to the definitions "Type (of an $<\mathrm{X}>$ )" (Part 2, Clause 9.7), "Class (of $<X>$ s)" (Part 2, Clause 9.8), " $<X>$ Template" (Part 2, Clause 9.11), and it shows that by defining and using the concepts of "role templates" and "role types" (so in their view a "role" is just another kind of " $<\mathrm{X}>$ "). It seems unclear from definition 2 whether roles have the same standing as in definition 1 (and whether the concept of role can be used to derive role templates, role types, etc.). This seems to be the most important (potential) point of contention in the definitions, and an important issue to settle.

An important issue for a definition for role that appears to be missing from definition 1 (and [2]) is the act of creating a "role instance", which is the point from which a particular object has the potential of exhibiting the behaviour that is expected in the collaborative behaviour in which the role is defined. This act is analogous to the act of binding of interfaces, which is the point from which interactions may occur in the context of the binding. The need for such an act is clearly justified in [13]: "the key idea is that some constraints on a system behaviour are associated with objects dynamically as a consequence of an earlier part of the behaviour, such as performance of a piece of negotiation", “[...] we need to clarify the way the potential behaviour of an object is restricted when it is bound to a role".

Definition 2, in contrast, talks about the "instantiation process" of the composite object. This instantiation process is composed of several actions, some of which "bind" a role to a specific object: "The instantiation process binds a specific component object of the resultant composite object to each role parameter." [11]. This seems to suggest that each "role parameter" must be "bound" to a specific component object to complete the instantiation process of the composite object. Naturally, no collaborative behaviour can occur without the composite object being instantiated. Some attention is required here to ensure that genuine usage of the concept is not prevented. For example, this sentence of the definition may prevent the "binding" of employees to the role of members of an organization's board without the existence of a secretary to the board (even if the role of secretary is not an essential part of the organization's board). In order to model this kind of situation, one would have to consider composite objects for each of the pairs of member and the board (since their lifecycles is independent, this seems to be a very reasonable way of modelling it.) An alternative option would be to allow for the definition of the composite object with non-mandatory roles which may be bound to a specific 
component, but are not required to complete the instantiation process of the composite object.

\subsection{An intermediate conclusion}

After the examination of these two proposals, we formulate the following proposal for a theory for the role concept:

(i) a theory for the role concept should account for the act of "binding a role" (or it should at least "capture the way in which the potential behaviour of an object is modified by creation of a community and by the object filling a community-role;" [13]);

(ii) a theory for the role concept should provide the same standing for the concept of role and other concepts which can be applied in sentences such as " $<\mathrm{X}>$ template", as argued for in [1]. Although this requirement is not explicitly mentioned in $[11,13]$, Linington has (in [13]) used the term "role binding" as a noun: "the lifetime of the role binding is always within the lifetime of the defining object", suggesting that such a role binding is an instance that deserves treatment in a theory for roles.

We argue that the literature on conceptual modelling provides us with such a suitable theory for roles.

\section{Roles in conceptual modelling}

We proceed by examining the understanding of the concept of role in conceptual modelling, which requires some preliminary definitions We use an extract from a philosophically and cognitively well-founded reference ontology (foundational ontology) that has been developed in $[5,6]$.

First, we distinguish between conceptual entities called universals and individuals [1]. The notion of universal underlies the most basic and widespread constructs in conceptual modelling. Universals are predicative terms that can possibly be applied to a multitude of individuals, capturing the general aspects of such individuals. Indi- viduals are entities that exist possessing a unique identity.

Figure 1 shows an extract of the foundational ontology adopted here (all generalization relations depicted in this figure are disjoint, forming a simple "tree-like" taxonomic structure for the entities considered in this model.)

This taxonomic structure reveals that an individual can be categorized as substantial or moment [10]. A moment is an individual that existentially depends on other individuals, named its bearers. In the conceptual modelling literature, a moment is said to inhere in its bearer(s). For example, the symptoms of a patient are said to inhere in the patient, who bears the symptoms. In contrast, a substantial is an individual that does not inhere in other individuals, i.e., which is not a moment. Inherence is much stronger than a one-to-one relationship, since it implies existential dependence between individuals. We have that an individual $x$ is existentially dependent on another individual $y$ if, and only if, as a matter of necessity, $y$ must exist whenever $x$ exists. (A moment may also inhere in another moment, the moments forming a finite chain that ends with a substantial.)

In this paper, we characterize "objects" (in the RMODP sense) as substantials and we explain the rolerelated notions in terms of moments. We use metaproperties of universals (namely, existential dependence, external dependence and anti-rigidity) to clarify certain aspects of these RM-ODP concepts.

\subsection{Qua individuals and relators}

The taxonomic structure presented in Figure 1 reveals a kind of individual which is of particular importance to the definition of role (in gray on the right side of the figure): a "QuaIndividual".

An example discussed in [7] clarifies this concept. Suppose that John is married to Mary. John is bound to certain behaviour by virtue of being married to Mary. For example, imagine all the legal responsibilities that John has in the context of this relation. This newly acquired behaviour is a moment of John that inheres in him (and is

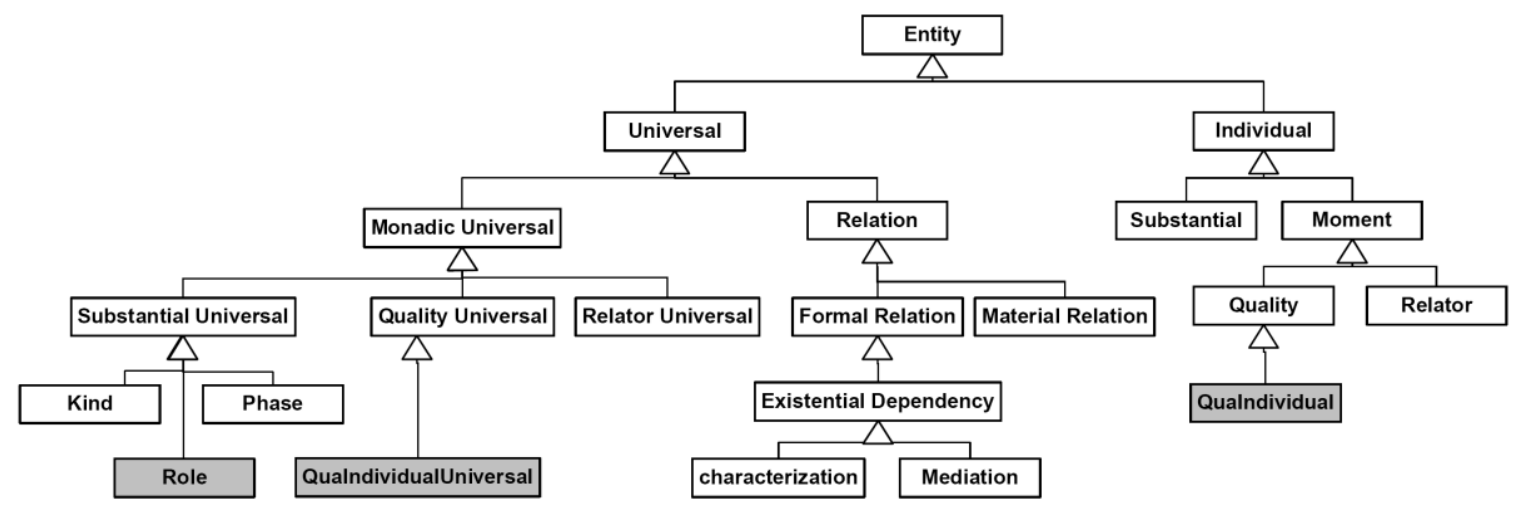

Figure 1 Extract of the foundational ontology adopted here from [7] 
hence existentially dependent on John). However, this moment also depends on the existence of Mary. This type of moment is called externally dependent moment. An externally dependent moment is an intrinsic moment (or quality) that inheres in a single individual but that is existentially dependent on (possibly a multitude of) other individuals.

In the case of an externally dependent moment $x$ there is always an individual external to its bearer (i.e., which is not one of its parts or intrinsic moments), which is the foundation of $x$. Again, in the given example, we can think of a certain action $a 1$ (the signing of a social contract) in which both John and Mary participate and which founds the existence of these externally dependent moments inhering in John. Now, we can define an individual that bears all externally dependent moments of John that share the same external dependencies and the same foundation. This individual is called a qua individual [14]. Qua individuals are, thus, a special type of complex externally dependent qualities. In this case, the complex quality inhering in John that bears all responsibilities that John acquires by virtue of the signing of a social contract can be named John-qua-husband.

To continue with the same example, we can think about another qua individual Mary-qua-wife which is a complex moment bearing all responsibilities that Mary acquires by virtue of the same foundation and that albeit inhering in Mary are also existentially dependent on John. The qua individuals John-qua-husband and Mary-qua-wife are existentially dependent on each other. Now, we can define an aggregate composed of these two qua individuals that share the same foundation. This aggregate is called a relator.

\subsection{Role universals}

The taxonomic structure in Figure 1 also reveals a "Role" universal. A "Role" universal applies contingently to an individual that bears (at least one) qua individual of a certain type. In the example presented in the previous sub-section, we can say that John is not only an instance of a "Person" universal but also an instance of a "Husband" universal, while Mary is both an instance of a "Wife" universal. All instances of a "Husband" universal exhibit the behaviour required of a husband in a social contract (marriage).

At the same time John may play the role of student with respect to an "Educational Institution" for example, the University of Twente. In this case, John bears a qua individual John-qua-student, and is an instance of the "Student" universal (John can register to courses, receive grades, produce assignments, take exams, etc.). Further, John may also play the role of student with respect to other "Educational Institutions", for example, the Tai Chi Institute - bearing then qua individuals: John-qua-student of the University of Twente and John-qua-student' of the Tai Chi Institute.

We can say that roles universals can be restricted by certain allowed types, i.e., certain universals to which a role universal can apply. For example, in this case, we can say that the "Student" role can only be played by an instance of the substantial universal "Person". Figure 2 shows a class diagram for this example, using the profile defined in [5]. The characterization association represents that instances of "PersonQuaStudent" inhere in an instance of "Student" (thus characterizing its behaviour).

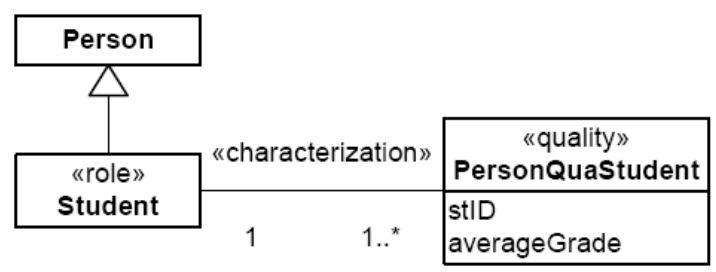

Figure 2 A role universal, its allowed type and a qua individual universal (from [5])

Figure 3 reveals the Enrolment relator universal (an instance of this universal includes an instance of "PersonQuaStudent"). The relator universal reveals that both an instance of "Student" and an instance of the "Education Institution" exhibit particular properties (shared behaviour) in the relation. Please note that properties are merely a dual way to represent behaviour.

\subsection{Role mixin universals}

The conceptualization in [5] also allows for a notion of role mixin universal which captures commonalities in various role universals. This universal is used in a conceptual modelling design pattern for "roles with multiple dis-

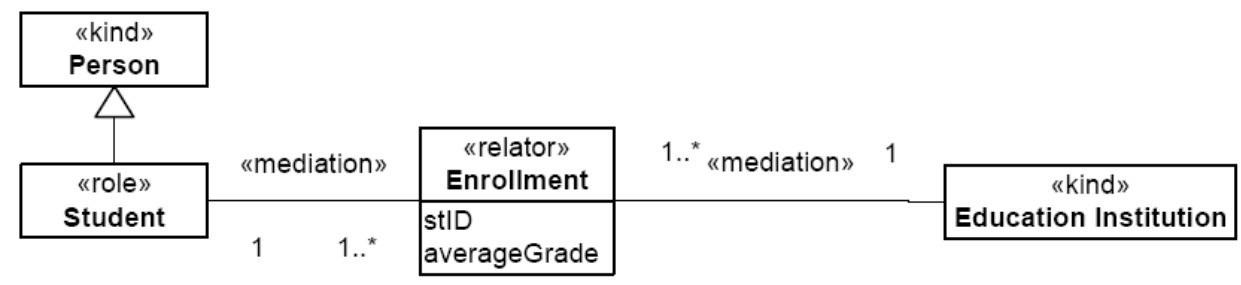

Figure 3 A role universal, its allowed type and a relator universal (from [5]) 
joint allowed types" (see Figure 4). (We omit the description of role mixins from this paper, please see [5] for a comprehensive discussion and characterization of a role mixin as an anti-rigid non-sortal universal.) Intuitively, a role mixin universal allows us to add flexibility to a role universal, without tying its definition to a specific sortal universal. In the example, it is possible to define a Customer independently of whether Persons or Organizations play that role.

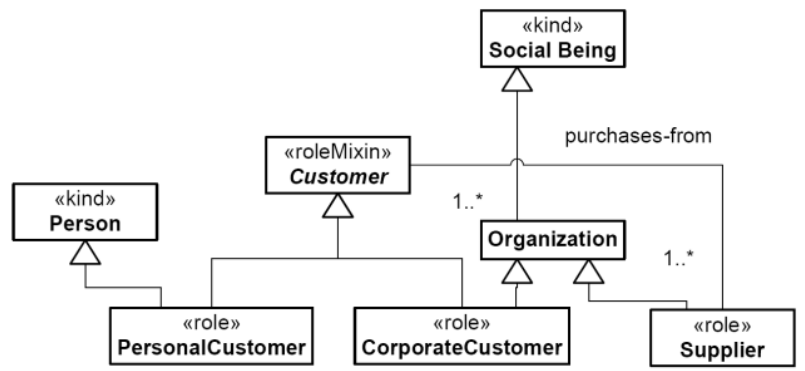

Figure 4 Modelling roles with multiple disjoint allowed types (an example from [5])

\section{Concept analysis}

We can now contrast the definitions provided in section 2 in the light of the UFO-A conceptualization described in section 3 . We also review the terms related to bindings in the Foundations [12] (sections 11 and 13 of Part 2) in the light of the conceptualization.

\subsection{Genilloud and Wegmann's definition 1}

In [1], Genilloud and Wegmann conclude that the "term role may denote an instance concept (role instance), a type for role instances (role type) or a type for objects (role object type). A role instance is therefore not a type, and role is to be considered as an $\langle\mathrm{X}>$ in the RM-ODP." Further they note that "[...] a modeller specifies role templates or collaborative behaviour templates".

Based on these observations a correspondence between the concepts defined by these authors and the UFO-A conceptualization is shown in Table 1. Please note that while universals are genuine concepts of conceptualizations such as UFO-A, the RM-ODP Foundations do not

\begin{tabular}{|c|c|c|}
\hline UFO-A & Genilloud and Wegmann & Example \\
\hline $\begin{array}{l}\text { qua individual } \\
\text { A qua individual is the instance that is founded } \\
\text { on a certain event or establishing behaviour, } \\
\text { which characterizes the individual with certain } \\
\text { behaviour in the context of a relation to another } \\
\text { individual. }\end{array}$ & "role instance" & $\begin{array}{l}\text { John-qua-husband; } \\
\text { Mary-qua-wife; } \\
\text { John-qua-student (of the University } \\
\text { of Twente); } \\
\text { John-qua-student' (of The Tai Chi } \\
\text { Institute). }\end{array}$ \\
\hline $\begin{array}{l}\text { (elementary specification of a) qua individual } \\
\text { universal }\end{array}$ & $\begin{array}{l}\text { "role template" or } \\
\text { "role type" }\end{array}$ & $\begin{array}{l}\text { Person-qua-Husband; } \\
\text { Person-qua-Wife; } \\
\text { Person-qua-Student; } \\
\text { (a supertype of Person-qua- } \\
\text { Customer, and Organization-qua- } \\
\text { Customer - not mentioned explic- } \\
\text { itly.) }\end{array}$ \\
\hline $\begin{array}{l}\text { (elementary specification of a) role universal } \\
\text { A role universal applies(contingently) to in- } \\
\text { stances of the role's allowed type. }\end{array}$ & \multirow[t]{2}{*}{ "role object type" } & $\begin{array}{l}\text { Husband; Wife; Student; } \\
\text { PersonalCustomer; } \\
\text { CorporateCustomer. }\end{array}$ \\
\hline $\begin{array}{l}\text { (elementary specification of a) role mixin } \\
\text { These universals apply (contingently) to in- } \\
\text { stances of disjoint allowed types. }\end{array}$ & & Customer \\
\hline relator & $\begin{array}{l}\text { aggregate of "role instances" } \\
\text { (not mentioned explicitly) }\end{array}$ & $\begin{array}{l}\text { John and Mary's marriage; } \\
\text { John's enrolment at the University } \\
\text { of Twente; } \\
\text { John's enrolment at the Tai Chi } \\
\text { Institute. }\end{array}$ \\
\hline (elementary specification of a) relator universal & $\begin{array}{l}\text { aggregate of "role templates" } \\
\text { (not mentioned explicitly) }\end{array}$ & $\begin{array}{l}\text { Marriage (this kind of social con- } \\
\text { tract); } \\
\text { Enrolment (this kind of social con- } \\
\text { tract). }\end{array}$ \\
\hline
\end{tabular}

Table 1 Correspondence between role-related concepts in UFO-A and those proposed by Genilloud and Wegmann 
include basic modelling concepts that correspond directly to universals. Instead, the RM-ODP notions of "type" and "template" are specification concepts that correspond not to universals but to elementary specifications of universals [5].

\subsection{Peter Linington's definition 2}

A correspondence between the concepts defined in the Working Draft of the Amendment to the Foundations [11] and [13] and those in the UFO-A conceptualization is shown in Table 2. We have included the term "role binding" here, although this term is used in [13] but not ex-

\begin{tabular}{|c|c|c|}
\hline UFO-A & Linington & Examples \\
\hline $\begin{array}{l}\text { qua individual } \\
\text { A qua individual is the instance that } \\
\text { characterizes the individual with } \\
\text { certain behaviour in the context of a } \\
\text { relation to another individual. }\end{array}$ & $\begin{array}{l}\text { "the behaviour of some component ob- } \\
\text { ject within the composite" } \\
\text { The behaviour of an object when it is "is } \\
\text { said to fulfil the role" or when it is } \\
\text { "bound to a role" [13]. }\end{array}$ & $\begin{array}{l}\text { John-qua-husband; Mary-qua-wife; } \\
\text { John-qua-student (of the University of } \\
\text { Twente); John-qua-student' (of the Tai } \\
\text { Chi Institute). }\end{array}$ \\
\hline $\begin{array}{l}\text { (elementary specification of a) qua } \\
\text { individual universal }\end{array}$ & $\begin{array}{l}\text { Part of a "template for a composite ob- } \\
\text { ject", since the template defines required } \\
\text { behaviour for objects fulfilling roles. }\end{array}$ & $\begin{array}{l}\text { Person-qua-Student; } \\
\text { Person-qua-Husband; } \\
\text { Person-qua-Wife. }\end{array}$ \\
\hline $\begin{array}{l}\text { the foundation of the qua individu- } \\
\text { als (and hence the foundation of the } \\
\text { relator) For example, a founding } \\
\text { action or behaviour. }\end{array}$ & "instantiation process" & $\begin{array}{l}\text { The signing of the social contract be- } \\
\text { tween John and Mary; The act of en- } \\
\text { rolling at the Univ. of Twente; The act } \\
\text { of enrolling at the Tai Chi Institute. }\end{array}$ \\
\hline $\begin{array}{l}\text { (elementary specification of a) role } \\
\text { universal } \\
\text { A role universal ap- } \\
\text { plies(contingently) to instances of } \\
\text { the role's allowed type. }\end{array}$ & $\begin{array}{l}\text { "role" (formal placeholder) } \\
\text { (Although this is not a strict correspon- } \\
\text { dence, since the specification of the uni- } \\
\text { versal is actually implied by the place- } \\
\text { holder.) }\end{array}$ & $\begin{array}{l}\text { Student; } \\
\text { Husband; } \\
\text { Wife; } \\
\text { PersonalCustomer; } \\
\text { CorporateCustomer. }\end{array}$ \\
\hline $\begin{array}{l}\text { (elementary specification of a) role } \\
\text { mixin } \\
\text { These universals apply (contin- } \\
\text { gently) to instances of disjoint al- } \\
\text { lowed types. }\end{array}$ & & Customer \\
\hline $\begin{array}{l}\text { an aggregate of all individuals that } \\
\text { are mediated by the relator }\end{array}$ & $\begin{array}{l}\text { "composite object" (as the term is used } \\
\text { in the scope of the definition of role) } \\
\text { "instantiation of the template" }\end{array}$ & $\begin{array}{l}\text { John and Mary; } \\
\text { John and the University of Twente; } \\
\text { John and the Tai Chi Institute. }\end{array}$ \\
\hline $\begin{array}{l}\text { an aggregate of the (elementary } \\
\text { specification of a) relator universal } \\
\text { and universals of the allowed types } \\
\text { for the roles involved }\end{array}$ & "template for a composite object" & $\begin{array}{l}\text { Person + Marriage (incl.Person-qua- } \\
\text { Husband and Person-qua-Wife) + Hus- } \\
\text { band + Wife; Person + Enrolment (incl. } \\
\text { Person-qua-Student) + Educational } \\
\text { Institution. }\end{array}$ \\
\hline $\begin{array}{l}\text { instance of the role universal } \\
\text { (individual which bears a qua indi- } \\
\text { vidual) } \\
\text { (instance of an allowed type for the } \\
\text { roles involved) }\end{array}$ & $\begin{array}{l}\text { "an actual object in an instantiation of } \\
\text { the composite" }\end{array}$ & $\begin{array}{l}\text { John; } \\
\text { Mary; } \\
\text { University of Twente; } \\
\text { Tai Chi Institute. }\end{array}$ \\
\hline relator & "role binding" & $\begin{array}{l}\text { John and Mary's marriage; John's en- } \\
\text { rolment at the Univ. of Twente; John's } \\
\text { enrolment at the Tai Chi Institute. }\end{array}$ \\
\hline $\begin{array}{l}\text { (elementary specification of a) rela- } \\
\text { tor universal }\end{array}$ & $\begin{array}{l}\text { part of a "template for a composite ob- } \\
\text { ject", since the template defines required } \\
\text { behaviour of the various that may par- } \\
\text { ticipate in the composite object }\end{array}$ & $\begin{array}{l}\text { Marriage (this kind of social contract) } \\
\text { Enrolment (this kind of social contract) }\end{array}$ \\
\hline
\end{tabular}

Table 2 Correspondence between role-related concepts in UFO-A and those proposed for the amendment of the Foundations 


\begin{tabular}{|c|c|c|}
\hline UFO-A & Structuring concepts & Examples \\
\hline qua individual & $\begin{array}{l}\text { part of an "enabled behaviour" } \\
\text { (since the "enabled behaviour" ac- } \\
\text { tually "characterizes a set of ob- } \\
\text { jects") }\end{array}$ & \begin{tabular}{|l} 
John-qua-husband \\
Mary-qua-wife \\
John-qua-student (of the University of Twente) \\
John-qua-student (of the Tai Chi Institute) \\
\end{tabular} \\
\hline $\begin{array}{l}\text { the foundation of the qua indi- } \\
\text { viduals (and hence the founda- } \\
\text { tion of the relator) } \\
\text { For example, a founding action } \\
\text { or behaviour. }\end{array}$ & an "establishing behaviour" & $\begin{array}{l}\text { The signing of the social contract between John } \\
\text { and Mary. } \\
\text { The act of enrolling at the University of Twente. } \\
\text { The act of enrolling at the Tai Chi Institute. }\end{array}$ \\
\hline $\begin{array}{l}\text { (elementary specification of a) } \\
\text { qua individual universal }\end{array}$ & $\begin{array}{l}\text { part of the "specification of a con- } \\
\text { tract" }\end{array}$ & $\begin{array}{l}\text { Person-qua-Student } \\
\text { Person-qua-Husband } \\
\text { Person-qua-Wife }\end{array}$ \\
\hline $\begin{array}{l}\text { (elementary specification of a) } \\
\text { role universal } \\
\text { A role universal ap- } \\
\text { plies(contingently) to instances } \\
\text { of the role's allowed type. }\end{array}$ & $\begin{array}{l}\text { part of the "specification of a con- } \\
\text { tract" }\end{array}$ & \begin{tabular}{|l} 
Student \\
Husband \\
Wife \\
PersonalCustomer \\
CorporateCustomer \\
\end{tabular} \\
\hline $\begin{array}{l}\text { (elementary specification of a) } \\
\text { role mixin } \\
\text { These universals apply (contin- } \\
\text { gently) to instances of disjoint } \\
\text { allowed types. }\end{array}$ & & Customer \\
\hline $\begin{array}{l}\text { instance of the role universal } \\
\text { (individual which bears a qua } \\
\text { individual) } \\
\text { (instance of an allowed type for } \\
\text { the roles involved) }\end{array}$ & "object" in the liaison & $\begin{array}{l}\text { John } \\
\text { Mary } \\
\text { University of Twente } \\
\text { Tai Chi Institute }\end{array}$ \\
\hline relator & $\begin{array}{l}\text { "liaison" which represents the "en- } \\
\text { abled behaviour" }\end{array}$ & $\begin{array}{l}\text { John and Mary's marriage } \\
\text { John's enrolment at the University of Twente } \\
\text { John's enrolment at the Tai Chi Institute. }\end{array}$ \\
\hline $\begin{array}{l}\text { (elementary specification of a) } \\
\text { relator universal }\end{array}$ & $\begin{array}{l}\text { "contract" ("specification of a con- } \\
\text { tract") }\end{array}$ & $\begin{array}{l}\text { Marriage (this kind of social contract) } \\
\text { Enrolment (this kind of social contract) }\end{array}$ \\
\hline
\end{tabular}

Table 3 Correspondence between role-related concepts in UFO-A and ODP's structuring concepts

plained explicitly and not included in the proposal for amendment of the standard [11].

This is somehow part of the "composite object", although it is hard to define which part in terms of definition 2 , since it is about part of the agreed behaviour of the composite object.

\subsection{Contracts, liaisons, establishing and en- abled behaviours (structuring concepts)}

From the discussion so far, it is clear that the notion of role is closely related to the notion of certain required behaviour in the context of a collaborative behaviour. In this context, a number of concepts defined in the RMODP Foundations are relevant. We quote the following definitions (we have underlined certain terms to emphasize the relations between concepts relevant to this discussion) [12]:
"11.2.1 Contract: An agreement governing part of the collective behaviour of a set of objects. A contract specifies obligations, permissions and prohibitions for the objects involved. The specification of a contract may include

a) a specification of the different roles that objects involved in the contract may assume, and the interfaces associated with the roles; b) quality of service attributes (see 11.2.2); c) indications of duration or periods of validity; d) indications of behaviour which invalidates the contract; e) liveness and safety conditions. 13.2.1 Establishing behaviour: The behaviour by which a given contract is put in place between given objects. An establishing behaviour can be:

a) explicit, resulting from the interactions of objects that will take part in the contract; orb) implicit, being performed by an external agency (e.g. a third party object, not taking part in the contract) or having been performed in a previous epoch.

13.2.2 Enabled behaviour: The behaviour characterizing a set of objects which becomes possible as a result of establishing behaviour. 
13.2.3 Contractual context: The knowledge that a particular contract is in place, and thus that a particular behaviour of a set of objects is required.

An object may be in a number of contractual contexts simultaneously; the behaviour is constrained to the intersection of the behaviours prescribed by each contractual context.

13.2.4 Liaison: The relationship between a set of objects which results from the performance of some establishing behaviour; the state of having a contractual context in common.

A liaison is characterized by the corresponding enabled behaviour.

NOTES 1 - Examples of liaisons which result from different establishing behaviours area) a dialogue (as in OSI-TP);b) a binding (see 13.4.2); [...]

13.4.1 Binding behaviour: An establishing behaviour between two or more interfaces (and hence between their supporting objects).

NOTE - "To bind" means "to execute a binding behaviour".

13.4.2 Binding: A contractual context, resulting from a given establishing behaviour.

Establishing behaviour, contractual context and enabled behaviour may involve just two object interfaces or more than two.

An object which initiates an establishing behaviour may or may not take part in the subsequent enabled behaviour.

Enabled behaviour (and, by analogy, contractual context) may be uniform (i.e. each participating object can do the same as every other) or non-uniform (i.e. one participating object has a different role from another, as in client and server).

There is no necessary correspondence between an object which initiates establishing behaviour and a particular role in nonuniform enabled behaviours (e.g. in a client-server contractual context, either object could validly have initiated the establishing behaviour)."

A correspondence between these concepts the UFO-A conceptualization is shown in Table 3 (ignoring here the implications for role-related concepts). Please note that, from the definitions in the Foundations it is hard to conclude what the difference between a "contractual context" and a "liaison" is: clause 13.2.4 says that a "binding" is an example of "liaison", and then clause 13.4.2 defines a "binding" as a "contractual context". So, for this comparison, we ignore contractual context, assuming for the time being that it is a synonym for liaison. (It is possible that the distinction between contractual context and liaison actually lies in the distinction between relators and material relations [7], but this is unclear from the current text, so we will not elaborate on this further.)

\section{A Note on "rigidity" of role universals}

As we have discussed in section 2 , both definitions 1 and 2 define that roles are always used in the scope of a particular relationship between objects, in the context of which the objects are said to be fulfilling roles exhibit particular (contingent) behaviours. We believe that both definitions however, unnecessarily require the notion of role to be used exclusively when other roles are involved ${ }^{1}$.

The example where John studies at the University of Twente clarifies that. The University of Twente is an instance of the "Education Institution" universal (so correspondingly, there is a template from which the University of Twente object can be instantiated). A definition of "Education Institution" is that it behaves in a certain way with respect to students (i.e., it executes some shared or collaborative behaviour with students.) It does so, however, necessarily, since the behaviour towards students is established in the definition of what an Education Institution is. The University of Twente is thus not playing the role of Education Institution in the context of a particular relation with a student. We believe there is no need to force the designer to use a role here or to imply that there is a role even if it is not modelled. (Of course one could always imagine that we could model the University of Twente as an "Institution" and then define an "Education Institution" role to be played by the university. Nevertheless, forcing this kind of construct would unnecessarily restrict the generality of the foundations.) The issue is further aggravated in the presence of "singletons" in specifications, such as, e.g., the definition of roles such as "President of Brazil" (relevant in Enterprise specifications), which relates the object "Brazil" to a "Person" playing the role of "President". (Of course, again, one could define that there is a country B playing the role of "Brazil" or that there is an object "Brazil" playing the role of country, but this is beyond the point being made here namely that the modeller should have the freedom to define roles with respect to a particular object of special interest to the shared behaviour.)

A rewriting of definition 2 to address this remark is simple: where it states that "the template for a composite object is specified as a composition of roles" we should say "the template for a composite object is specified as a composition which may include other roles."

A rewriting of the note 1 in definition 1 would also solve this issue: where it states that: "The collaborative behaviour of a role represents the specific context in which it is defined, together with other roles. All the interactions of a role are with the roles with which it is defined. And all the actions in a collaborative behaviour belong to one or more of its roles." we should say "The collaborative behaviour of a role represents the specific context in

\footnotetext{
${ }^{1}$ Definition 1 includes a note that states that: "The collaborative behaviour of a role represents the specific context in which it is defined, together with other roles. All the interactions of a role are with the roles with which it is defined. And all the actions in a collaborative behaviour belong to one or more of its roles." Definition 2 states that "the template for a composite object is specified as a composition of roles".
} 
which it is defined, together with other roles, objects and interfaces required. All the interactions of a role are with the roles, objects and interfaces required in its definition."

This is in line with the ideas defended by Guarino and Welty in [4] where a role universal is defined as an antirigid universal. An anti-rigid universal is a universal that applies contingently to its instances, while a rigid universal is a universal that applies necessarily to its instance in every possible situation considered by the model. As opposed to instances of an anti-rigid universal, instances of a rigid type will continue to be so as long as they exist in the model. Guarino and Welty (in [4]) use the student example to clarify these definitions: "Obviously there are also properties that are not essential to all their instances. Of these we distinguish properties that are essential to some entities and not essential to others (semi-rigid) from properties that are never essential (anti-rigid). For example, the property being a student is typically anti-rigid-every instance of student is not essentially a student (may also be a non-student), whereas the property being hard is semi-rigid, since there are instances (hammers) that must be hard and instances (sponges) that may be hard but also may not." Definitions for rigidity, semi-rigidity and antirigidity have been formalized in [5].

Finally, we should say that it is not necessary to include the requirement of anti-rigidity for templates in the foundations of RM-ODP, but we should not include a definition that forces one to consider roles that are rigid (as in the example of the educational institution described above). For this reason we should also modify definition 2 which states in a note that: "Note - Any agreement governing shared behaviour of two or more objects implicitly defines a template for a composite object and the roles of those objects in that composite object. Thus, roles are defined by interactions (8.3), contracts (11.2.1), liaisons (13.2.4) and bindings (13.4.2)." We should be more careful and say instead that "A particular specification language may consider that any agreement governing shared behaviour of two or more objects implicitly defines a template for a composite object and the roles of those objects in that composite object. Thus, in these cases, roles may be defined by interactions (8.3), contracts (11.2.1), liaisons (13.2.4) and bindings (13.4.2)"

\section{Conclusions}

We hope to have contributed for a definition of rolerelated concepts in the foundations of RM-ODP that harmonizes proposals that have been defined so far and that are well-positioned with respect to the literature in conceptual and object-oriented modelling. (For an extensive discussion on roles in the conceptual modelling literature that justify the UFO-A conceptualization see $[5,7]$.)
We have appreciated very much the parallel between interfaces and roles as defended in [1]. We believe the authors should have taken the parallel further: in the same way as one can use the concepts of "establishing behaviour", "liason", "creation", etc. in the context of "interfaces" one should also be able to do that for "role instances". We have also appreciated very much the definition provided in [11], which mentions an "instantiation process" for "composite objects", which prompted us to investigate the relation of the role concept with the Foundation structuring concepts.

By no means have we intended to suggest that the terminology used in conceptual modelling should find its way in the RM-ODP. Nevertheless, we strongly believe that the Foundations ought to be based on well-founded conceptualizations that should not preclude valid and genuine conceptual constructions. We have yet to come to a proposal for a text that captures the issues discussed here. A table in the appendix summarizes the various correspondences presented in this paper and is the starting point for a concrete proposal.

We concluded that the notion of role in RM-ODP is also closely related to notions of relation or relationship, and that it is important to examine these definitions closely. Linington justifiably notes in [13] an important omission in the current standard: "One example is the omission of terms in common technical usage, such as relationship or association, definitions of which should be included on the basis of significant usage in ODP specification, even if they seem obvious. The Foundations should include generic definitions consistent with, but less detailed and restrictive than those in the ISO General Relationship Model" [9].

We believe that introducing definitions for these concepts may support role-related definitions, and result in a more comprehensive foundation. We have also pointed that the structuring concepts in the Foundations should also be included in this discussion, as the definitions are closely related. We intend to address these issues in future work, possibly, relating also the RM-ODP Foundations to the concepts in the UML specification [17], and analysing the possible impact on the proposed standard on UML for ODP systems specification [10]. (Aligning all the definitions is certainly a great challenge, considering also the GRM [9], the standard on bindings [8] and the RM-ODP Enterprise Language.)

In $[5,7]$ the conceptualization provided here is defined formally, in order to allow for unambiguous interpretation of the intended semantics for concepts. Similarly to the formalization sketched in [13], it is not the intention that average users of these concepts should be concerned with the considerations required for formalization, but that one may use the formalization as a tool in interpreting the definitions in the standard. 


\section{Acknowledgements}

This work is part of the Freeband A-MUSE project (http://a-muse.freeband.nl), which is sponsored by the Dutch government under contract BSIK 03025, and the INFRA-MODELA project, which is sponsored by FAPES (Fundação de Apoio à Ciência e Tecnologia do Espírito Santo). The authors would like to thank Patrícia Dockhorn Costa for fruitful discussions about some issues addressed in this paper.

\section{References}

1. G. Genilloud, A. Wegmann, "A Foundation for the Concept of Role in Object Modelling", Proc. Int'l EDOC Conf. 2004, IEEE Computer Society Press, 2004.

2. G. Genilloud, A. Wegmann, "A New Definition for the Concept of Role, and Why it Makes Sense", OOPSLA Workshop on Behavioural Semantics, Oct. 2000.

3. N. Guarino, C. Welty, "Evaluating ontological decisions with OntoClean". Communications of the ACM, 45, 2, Feb. 2002, pp 61-65.

4. N. Guarino, C. Welty, "Identity and Subsumption. In The Semantics of Relationships: An Interdisciplinary Perspective", eds. R. Green, C. Bean and S. Myaeng,. Amsterdam, The Netherlands: Kluwer Academic, 2002, pp. 111-126.

5. G. Guizzardi, Ontological Foundations for Structural Conceptual Models, PhD Thesis, University of Twente, The Netherlands. TI-FRS No. 15, 2005.

6. G. Guizzardi, G. Wagner, "Towards Ontological Foundations for Agent Modeling Concepts using UFO", Lecture Notes on Artificial Intelligence (LNAI) 3508, Springer-Verlag, 2005.

7. G. Guizzardi, "Agent Roles, Qua Individuals and The Counting Problem", Invited Chapter in Software Engineering of Multi-Agent Systems, vol. IV, P. Giorgini, A.Garcia, C. Lucena, R. Choren (eds.), Springer-Verlag, 2006.

8. ITU-T Rec. X.930 (1998 E) | ISO/IEC 14753:1999, Information Technology - Open Distributed Processing Interface References and Binding, 1999.

9. ISO/IEC IS 10165-7, Information Technology - Open Systems Interconnection - Structure of management information: General relationship model, 1996.

10. ISO/IEC JTC1/SC7/WG19, Working Draft for ITU-T Recommendation X.906 | ISO/IEC 19793, Information technology - Open distributed processing - Use of UML for ODP system specifications, 2007.
11. ISO/IEC JTC1/SC7/WG19, Working Document Amendment to ITU T X.901-3 | ISO/IEC 10746 Information Technology - Open Distributed Processing - Reference Model, v01.23, 2007.

12. ISO / ITU-T, Open Distributed Processing - Reference Model - Part 2: Foundations, International Standard ISO/IEC 10746-2, ITU-T Recommendation X.902, 1995.

13. P.F. Linington, "What Foundations does the RM-ODP Need?", Proc. WODPEC 2004, IEEE Computer Society Press, 2005.

14. C. Masolo, G. Guizzardi, L. Vieu, E. Bottazzi, R. Ferrario, "Relational Roles and Qua Individuals", AAAI Fall Symposium on Roles, an Interdisciplinary Perspective, Virginia, USA, 2005.

15. K. Mulligan, B. Smith, A Relational theory of the Act. Topoi (5/2), 115-30, 1986.

16. Naumenko, "Triune Continuum Paradigm: a paradigm for General System Modeling and its applications for UML and RM-ODP”, Ph.D. Thesis number 2581, Swiss Federal Institute of Technology - Lausanne (EPFL), June 2002.

17. Object Management Group, UML 2.0 Infrastructure Specification, ptc/03-09-15, Sep. 2003.

18. F. Steimann, A Radical Revision of UML's Role Concept, in UML 2000: Proceedings of the 3rd International Conference, Springer-Verlag, 2000, pp. 194-209.

19. F. Steimann, "On the representation of roles in objectoriented and conceptual modelling," Data and Knowledge Engineering, vol. 35, pp. 83-106, 2000.

20. Wegmann, G. Genilloud, "The Role of 'Roles' in Use Case Diagrams", in UML 2000: Proceedings of the 3rd International Conference, Springer-Verlag, 2000.

21. R.J. Wieringa, W. de Jonge, P.A. Spruit. "Using dynamic classes and role classes to model object migration". Theory \& Practice of Object Systems, 1(1), 1995, pp 61-83. 


\begin{tabular}{|c|c|c|c|c|}
\hline UFO-A & Genilloud Wegmann & Linington & Structuring concepts & Examples \\
\hline $\begin{array}{l}\text { qua individual A qua individual is } \\
\text { the instance that characterizes the } \\
\text { individual with certain behaviour } \\
\text { in the context of a relation to an- } \\
\text { other individual. }\end{array}$ & "role instance" & $\begin{array}{l}\text { "the behaviour of some component } \\
\text { object within the composite" - The } \\
\text { behaviour of an object when it is "is } \\
\text { said to fulfil the role" or when it is } \\
\text { "bound to a role" [13]. }\end{array}$ & $\begin{array}{l}\text { part of an "enabled behav- } \\
\text { iour" (since the "enabled } \\
\text { behaviour" actually "char- } \\
\text { acterizes a set of objects") }\end{array}$ & $\begin{array}{l}\text { John-qua-husband; Mary-qua-wife; John-qua- } \\
\text { student (of the University of Twente); John- } \\
\text { qua-student' (of The Tai Chi Chuan Institute). }\end{array}$ \\
\hline $\begin{array}{l}\text { the foundation of the qua indi- } \\
\text { viduals (and hence the foundation } \\
\text { of the relator). For example, a } \\
\text { founding action or behaviour. }\end{array}$ & not available & \begin{tabular}{|l|l|} 
"instantiation process" & \\
& \\
\end{tabular} & $\begin{array}{l}\text { an "establishing behav- } \\
\text { iour" } \\
\text { (or a specialization of this } \\
\text { concept) }\end{array}$ & $\begin{array}{l}\text { the signing of the social contract; } \\
\text { the act of enrolling at the university; } \\
\text { the act of enrolling at the Tai Chi Chuan Insti- } \\
\text { tute. }\end{array}$ \\
\hline $\begin{array}{l}\text { an aggregate of all individuals } \\
\text { that are mediated by a relator }\end{array}$ & not applicable & $\begin{array}{l}\text { "composite object" (as the term is used } \\
\text { in the scope of the definition of role); } \\
\text { "instantiation of the template" }\end{array}$ & $\begin{array}{l}\text { aggregate of "objects" in a } \\
\text { "liaison" }\end{array}$ & $\begin{array}{l}\text { John and Mary; } \\
\text { John and the University of Twente; } \\
\text { John and the Tai Chi Chuan Institute. } \\
\end{array}$ \\
\hline $\begin{array}{l}\text { an aggregate of the (elementary } \\
\text { specification of a) relator univer- } \\
\text { sal and universals of the allowed } \\
\text { types for the roles involved }\end{array}$ & not applicable & "template for a composite object" & not applicable & $\begin{array}{l}\text { Person + Marriage (includes Person-qua- } \\
\text { Husband and Person-qua-Wife) + Husband + } \\
\text { Wife; Person + Enrolment (includes Person- } \\
\text { qua-Student) + Educational Institution. }\end{array}$ \\
\hline $\begin{array}{l}\text { instance of the role universal } \\
\text { (individual which bears a qua } \\
\text { individual) (instance of an al- } \\
\text { lowed type for the roles involved) }\end{array}$ & "object" & $\begin{array}{l}\text { "an actual object in an instantiation of } \\
\text { the composite" }\end{array}$ & "object" in the liaison & $\begin{array}{l}\text { John; } \\
\text { Mary; } \\
\text { University of Twente; } \\
\text { Tai Chi Chuan Institute. } \\
\end{array}$ \\
\hline relator & $\begin{array}{l}\text { aggregate of "role } \\
\text { instances" } \\
\text { (not mentioned ex- } \\
\text { plicitly) }\end{array}$ & \begin{tabular}{|l|} 
"role binding" (somehow part of the \\
"composite object", see section 4.2).
\end{tabular} & $\begin{array}{l}\text { "liaison" which represents } \\
\text { the "enabled behaviour" }\end{array}$ & $\begin{array}{l}\text { John and Mary's marriage; } \\
\text { John's enrolment at the University of Twente; } \\
\text { John's enrolment at the Tai Chi Chuan Insti- } \\
\text { tute. }\end{array}$ \\
\hline $\begin{array}{l}\text { (elementary specification of a) } \\
\text { relator universal }\end{array}$ & $\begin{array}{l}\text { aggregate of "role } \\
\text { templates" } \\
\text { (not mentioned ex- } \\
\text { plicitly) }\end{array}$ & \begin{tabular}{|l} 
part of a "template for a composite \\
object", since the template defines re- \\
quired behaviour of the various that \\
may participate in the composite object
\end{tabular} & $\begin{array}{l}\text { "contract" ("specification } \\
\text { of a contract") }\end{array}$ & $\begin{array}{l}\text { Marriage (this kind of social contract); } \\
\text { Enrolment (this kind of social contract). }\end{array}$ \\
\hline $\begin{array}{l}\text { (elementary specification of a) } \\
\text { qua individual universal }\end{array}$ & $\begin{array}{l}\text { "role template" or } \\
\text { "role type" }\end{array}$ & $\begin{array}{l}\text { Part of a "template for a composite } \\
\text { object", since the template defines re- } \\
\text { quired behaviour for objects fulfilling } \\
\text { roles. }\end{array}$ & $\begin{array}{l}\text { part of the "specification of } \\
\text { a contract" }\end{array}$ & $\begin{array}{l}\text { Person-qua-Student; } \\
\text { Person-qua-Husband; } \\
\text { Person-qua-Wife. }\end{array}$ \\
\hline $\begin{array}{l}\text { (elementary specification of a) } \\
\text { role universal } \\
\text { A role universal ap- } \\
\text { plies(contingently) to instances of } \\
\text { the role's allowed type. }\end{array}$ & "role object type" & $\begin{array}{l}\text { "role" (formal placeholder) } \\
\text { (Although this is not a strict correspon- } \\
\text { dence, since the specification of the } \\
\text { universal is actually implied by the } \\
\text { placeholder.) }\end{array}$ & $\begin{array}{l}\text { part of the "specification of } \\
\text { a contract" }\end{array}$ & $\begin{array}{l}\text { Husband; } \\
\text { Wife; } \\
\text { Student; } \\
\text { PersonalCustomer; CorporateCustomer. }\end{array}$ \\
\hline $\begin{array}{l}\text { (elementary specification of a) } \\
\text { role mixin } \\
\text { These universals apply (contin- } \\
\text { gently) to instances of disjoint } \\
\text { allowed types. }\end{array}$ & & & & Customer \\
\hline
\end{tabular}

Table 4 Summary of the correspondence in role-related concepts 